\title{
GIS-based modeling for the spatial measurement and evaluation of mixed land use development for a compact city
}

\begin{abstract}
Compact cities are recognized as sustainable urban forms rather than sprawl developments. Such cities are characterized by high density, land use diversity, accessibility, and efficient public transportation. However, few studies investigate how and how much these parameters affect and relate to compact cities. For instance, although mixed land use is the main key planning principle of compact development, no standard method exists for quantifying, measuring, and evaluating this parameter. This study performs a compact development analysis of Kajang City (Malaysia) with emphasis on evaluating and discussing the importance of mixed land use development. First, the land use diversity of Kajang City was measured. Second, the probability map of mixed land use developments was predicted using a weights-of-evidence (WoE) model. Finally, the importance of mixed land use for compact cities was evaluated using multicriteria decision analysis (MCDA). The created mixed land use probability map was validated using the receiver operating characteristic (ROC) technique. In addition, the 75\% similarity between mixed land use and compact development suitability maps highlighted the importance of mixed land use development for compact cities. Results can be used as preliminary guidelines for local governments and planners regarding compact development and management to achieve sustainable urban forms.
\end{abstract}

Keyword: Sustainable urban; Development; Compact city modeling; Mixed land use; Weights-of-evidence; GISremote sensing; Malaysia 